\title{
Menggunakan Konsep Inkarnasi Yesus sebagai Model Penginjilan Multikultural
}

Using the Concept of Jesus Incarnation as Multicultural Evangelism Model

\section{Febriaman Lalaziduhu Harefa}

Sekolah Tinggi Teologi Ebenhaezer Tanjung Enim

febriaman.harefa.h24@gmail.com

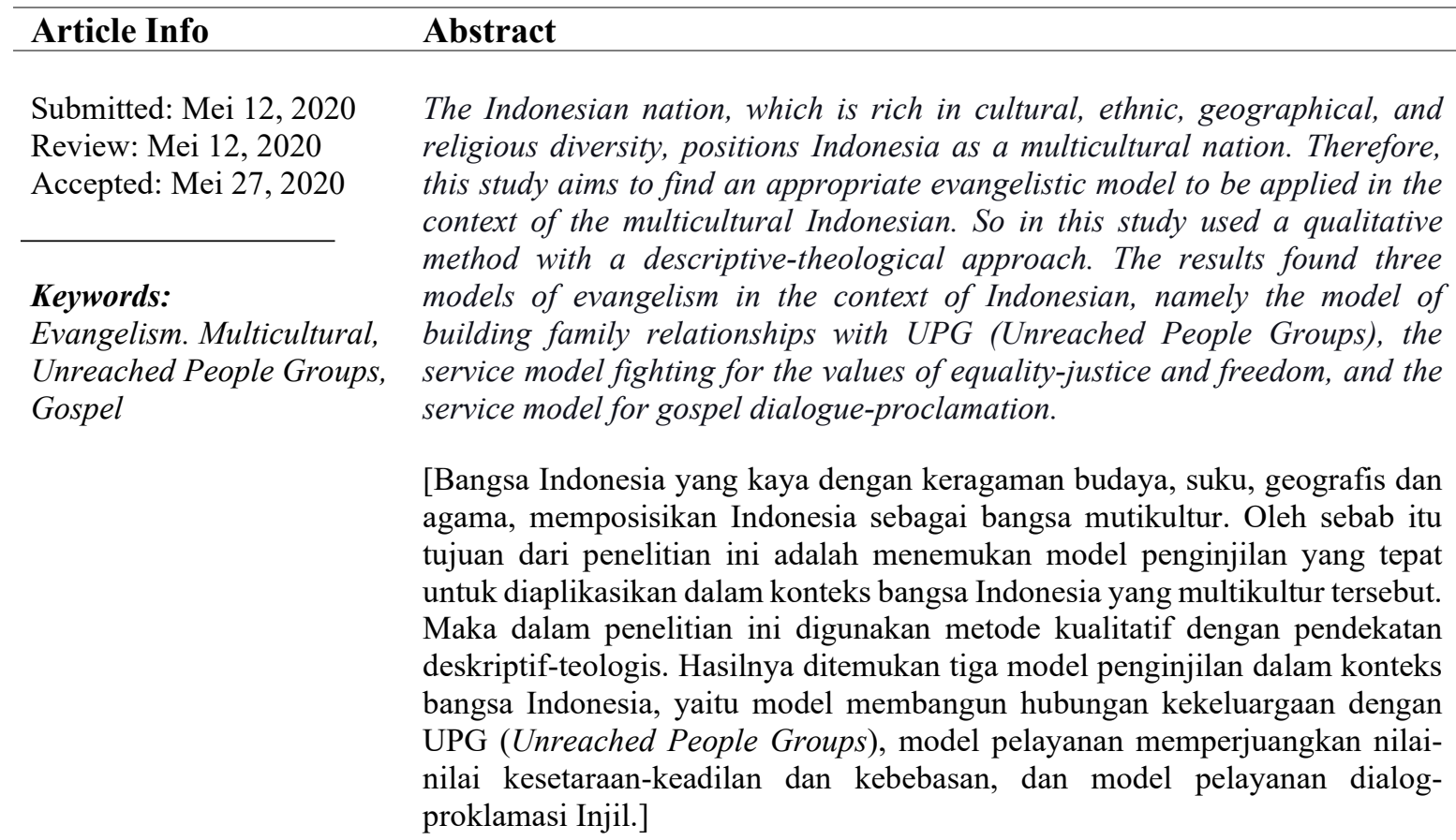




\section{PENDAHULUAN}

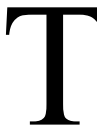
ugas pemberitaan Injil merupakan tugas serta tanggung jawab orang percaya, karena didasarkan kepada Amanat Agung yang tertulis di Matius 28:19-20. Di dalam menjalankan tugas dan tanggung jawab ini, Allah menghendaki keterlibatan orang percaya, memberitakan Kerajaan Allah di seluruh dunia. Lumintang menuliskan bahwa Amanat Agung ini bersifat otoratif, urgen dan mendesak, karena berhubungan dengan keselamatan jiwa-jiwa yang menuju pada kebinasaan. ${ }^{1}$ Dalam memproklamirkan berita Kerajaan Allah kepada UPG (Unreached People Groups), banyak tantangan yang dihadapi oleh para penginjil, khususnya dalam konteks bangsa Indonesia yang multikultur. Para penginjil biasanya menghadapi tantangan dari agama-agama yang memiliki keyakinan berbeda (tantangan religius), dari suku-suku, etnis-budaya yang berbeda (tantangan cultural) serta tantangan geografis. ${ }^{2}$

Tantangan ini dilatarbelakangi karena Indonesia adalah negara yang memiliki beragam suku, agama dan ras yang berbeda-beda terpampang dari Sabang sampai Merauke. ${ }^{3}$ Indonesia memiliki Jumlah penduduknya 220 juta jiwa, menempati urutan jumlah penduduk terbesar ke-4 dunia. Indonesia dikenal sebagai Negara kepulauan terbesar dengan 18.160 pulau, yang di dalamnya terdapat lebih kurang 366 etnis dan 350 bahasa suku yang berbeda. ${ }^{4}$ Selain itu, Indonesia juga dikenal sebagai Negara maritim dimana tiga per-empat wilayahnya (5,8 juta kilometer persegi) adalah lautan. ${ }^{5}$

Memperhatikan problematika ini, banyak pendekatan yang dirancang oleh para teolog sebagai solusi dalam memberitakan Injil dalam konteks Indonesia yang multikultur. Secara umum pendekatan yang telah dilakukan selama ini adalah pendekatan dalam konteks Teologi-Misiologis, yang diekspresikan dalam sikap Eksklusif, Inklusif dan Pluralis. Namun Sudarmanto menyebutkan bahwa pendekatan tersebut belum memadai dalam menjawab persoalan multikultur di Indonesia bahkan justru cenderung menimbulkan persoalan. ${ }^{6}$ Hal yang sama dituliskan oleh Sentot Sadono bahwa jikalau pendekatan ini dipaksa untuk dilakukan maka para praktisi misi di Indonesia terjabak kepada metode penginjilan yang tidak Alkitabiah. ${ }^{7}$

Menanggapi problematika di atas, beberapa penelitian dilakukan untuk menemukan solusi dan jawaban sebagai kontribusi bagi Penginjil dalam memberitakan Kerajaan Allah dalam konteks bangsa Indonesia yang multikultur. Beberapa penelitian yang dimaksud. Pertama, penelitian yang dilakukan oleh Winfrid Prayogi, yang menemukan tentang strategi mewujudkan Amanat Agung dalam konteks bergereja, baik dalam membahas tentang peranan gereja dalam menjalankan misi gereja di Indonesia memasuki awal abad-21. ${ }^{8}$ Penelitian Prayogi lebih menakankan kepada peranan gereja dalam mewujudkan panggilannya di dalam dunia, khususnya dalam konteks Indonesia yang multikultur. ${ }^{9}$ Kedua, penelitian Roedy Silitonga yang memaparkan signifikansi Amanat Agung di

${ }_{1}^{1}$ Stevri Indra Lumintang, Misiologia Kontemporer, 1st ed. (Batu: Departemen Literatur PPII, 2006).112

2 Desiana M. Nainggolan, "Multikulturalisme Untuk Teologi Misi Ramah Kemanusiaan," Jurnal Teologi Stulos 17, no. 2 (2019).215

${ }^{3}$ Fransiskus Irwan Widjaja, "Pluralitas Dan Tantangan Misi : Kerangka Konseptual Untuk Pendidikan Agama" 4 (2019): 2.

${ }^{4}$ Markus Dominggus L. Dawa, "Menjadi Jemaat Multikultural : Suatu Visi Untuk Gereja-Gereja Tionghoa Injili Indonesia Yang Hidup Di Tengah Konflik Etnis Dan Diskriminasi Rasial," Veritas : Jurnal Teologi Dan Pelayanan 7, no. 1 (2006): 127. https://doi.org/10.36421/veritas.v7il.157.

${ }^{5}$ Christia Spears Brown, Michelle Tam, and Frances Aboud, "Ethnic Prejudice in Young Children in Indonesia: Intervention Attempts Using Multicultural Friendship Stories," International Journal of Early Childhood 50, no. 1 (2018): 71, https://doi.org/10.1007/s13158-018-0214-z.

${ }^{6}$ Gunaryo Sudarmanto, Teologi Multikultural, ed. Dina Elisabeth Latumahina, 1st ed. (Batu: Departemen Multi-Media YPPII Batu, 2014).18

7 Sentot Sadono, "Misi Injili Dalam Konteks Masyarakat Indonesia Yang Majemuk," in Holistic Global Mission (Batu: Departemen Literatur YPPII, 2007). 320

${ }^{8}$ Winfrid Prayogi, "Mencari Esensi Dan Misi Gereja Dalam Konteks Indonesia Awal Abad 21," Veritas : Jurnal Teologi dan Pelayanan 1, no. 1 (2000): 39-51.

${ }^{9}$ Ibid.49-51 
dalam Matius 28:19-20 dan implikasinya dalam konteks bergereja di Indonesia. Silitonga memaparkan bahwa Amanat Agung, terimplementasinya dalam dua hal yaitu internal dan eksternal. Secara internal mencangkup baptisan, pemuridan dan pengajaran, sedangkan secara ekternal berhubungan dengan kegiatan pemberitaan Injil dan mengajarkan suku-suku bangsa menjadi murid Kristus. ${ }^{10}$ Ketiga, penelitian Nainggolan yang berusaha memaparkan konstruksi teologis untuk misi multikultural. Penemuanya tentang fondasi teologis ini menjadi rancang bangun dalam melakukan tugas proklamasi Injil yang ramah kemanusiaan dalam konteks UPG (Unreached People Groups) yang multikultur. Dalam hal ini, Nainggolan lebih cenderung meletakkan fondasi dan kerangka teologi misi dalam konteks multikultur. ${ }^{11}$

Memperhatikan penelitian di atas, penulis tergerak untuk menemukan suatu model penginjilan yang Alkitabiah dan kontekstual yang cocok diaplikasikan dalam konteks bangsa Indonesia yang multikultur. Berdasarkan prinsip-prinsip inkarnasi Yesus selama melayani di dunia. Artinya, penelitian ini bukan hanya memaparkan kerangka teologis tentang proklamasi Injil dalam konteks bangsa Indonesia. Atau hanya memaparkan implementasi Amanat Agung dalam konteks bergereja di Indonesia. Penelitian ini menyangkut kedua hal di atas, yaitu rancang bangun teologinya dan model-model penginjilannya. Harapanya adalah menemukan model penginjilan yang Alkitabiah dan kontekstual sesuai dengan konteks bangsa Indonesia yang multikultural. Berdasarkan prinsipprinsip inkarnasi Yesus seperti dilaporkan oleh Alkitab, karena selama Yesus melayani di dunia, melayani dalam konteks multikultur dan multietnis. Prinsip-prinsip pelayanan Yesus ini kemudian diimplementasikan dalam konteks bangsa Indonesia yang multikultur.

\section{METODE}

Penelitian ini membahas tentang Prinsip Inkarnasi Yesus Kristus Sebagai Model Penginjilan Dalam Konteks Bangsa Indonesia yang Multikultur. Maka metode yang digunakan dalam mendapatkan data adalah metode kualitatif dengan pendekatan deskriptif-teologis. ${ }^{12}$ Pertama-tama meneliti prinsipprinsip inkarnasi Yesus sebagaimana dituliskan di dalam Alkitab. Kemudian menemukan model pelayanan penginjilan yang dapat diaplikasikan dalam konteks bangsa Indonesia yang multikultur. Semua bahan yang dipergunakan bertumpu pada literature review seperti dimaksud oleh Hum. ${ }^{13}$

\section{PEMBAHASAN}

\section{Prinsip-Prinsip Inkarnasi Yesus}

Inkarnasi Yesus adalah doktrin yang paling pokok dalam kekristenan, karena menyangkut sejarah faktual yang diimani oleh orang Kristen sepanjang masa. ${ }^{14}$ Pada hakikatnya inkarnasi merupakan tindakan sakramental Allah yang melaluinya keselamatan dibawa ke dunia dan menunjukkan bahwa Yesus sudah pernah hadir dan menyatakan diri di dalam sejarah kehidupan manusia. ${ }^{15}$ Ia seorang tukang kayu dan pengkhotbah keliling yang berjalan di jalan-jalan berdebu di Galilea, mengajar di Sinagoge di Kapernaum, membersihkan Bait Allah dari penodaan para penukar uang di Yerusalem, pernah tertidur diburitan kapal. Pernah dicobai oleh iblis di padang gurun belantara, pernah menangis

${ }^{10}$ Roedy Silitonga, “Amanat Agung Dan Kemajemukan Agama,” Jurnal Teologi Stulos 16, no. Misi (2018): 69-89.

${ }^{11}$ Nainggolan, "Multikulturalisme Untuk Teologi Misi Ramah Kemanusiaan.”215

12 Sonny Eli Zaluchu, "Strategi Penelitian Kualitatif Dan Kuantitatif Di Dalam Penelitian Agama," Evangelikal 4, no. 1 (2020): 28-38.

${ }^{13}$ Yan Chai Hum, "Literature Reviews," in SpringerBriefs in Applied Sciences and Technology, 2013, 11-45.

${ }^{14}$ Peter Onyekwelu Okafor, "Incarnation As a Fundamental Hermeneutical Principle : The Case of Christian Theology and the Issue of Theological Education in Nigeria," Ministerium - Journal of Contextual Theology 2, no. 1 (2016): 1.

${ }^{15}$ Emily Paul, "Incarnation, Modality Timelessness, And,” 2019, 88. 
di kuburan Lazarus, merayakan perjamuan terakhir dengan para murid di ruang atas dan mati di kayu salib. ${ }^{16}$

\section{Pengertian Inkarnasi}

Istilah "Inkarnasi" terbentuk dari bahasa Latin yaitu "Incarnatus". Dimana kata ini terdiri dari dua kata yaitu "in" artinya "dalam" dan "carn/caro" artinya daging. Secara hurufiah artinya adalah masuk ke dalam daging. Inkarnasi artinya penjelmaan atau pengambilan wujud seperti manusia. ${ }^{17}$ Secara spesifik inkarnasi terdapat di dalam Yohanes 1:1-4 dan 14, dan Yohanes menjelaskannya dalam empat hal. Pertama, eksistensi Firman sebelum dunia dijadikan yaitu keberadaan-Nya kekal adanya bahkan telah ada sebelum segala sesuatu ada. Maka Firman itu adalah Pencipta dan segala sesuatu dijadikan oleh Dia. Kedua, Firman adalah Oknum/Pribadi dan Firman itu bersama-sama dengan Allah (tetapi berbeda dengan Allah). Ketiga, Walaupun Firman itu dibedakan dengan Allah, tetapi yang dimaksud teks Alkitab yaitu Firman adalah Allah. Dimana firman itu dinyatakan memiliki kesetaraan dengan Allah. Keempat, yang dimaksud dengan Firman di dalam teks Yohanes 1:14 adalah pribadi Firman (Anak Tunggal Allah) telah menjadi manusia dan hidup di tengah-tengah manusia. $^{18}$

Yohanes menjelaskan tentang inkarnasi dengan ungkapan yang sangat kuat karena menyebutkan tentang apa yang manusiawi bertentangan dengan apa yang ilahi, karena peristiwa inkarnasi merupakan kisah yang sangat sulit dipahami oleh akal pikiran manusia. Dibuktikan dalam konteks sejarah muncul beberapa pertanyaan dan keraguan tentang Yesus Kristus (Logos), bisa menjelma menjadi manusia. ${ }^{19}$ Tetapi Alkitab menyebutkan bahwa inkarnasi adalah peristiwa dan fakta sejarah, dimana Allah (Firman/Logos) telah menjadi daging atau manusia. Secara spesifik, Ia dilahirkan oleh perawan Maria (Mat. 1:18-23; Luk. 2:6-7). Ia menyatakan kepada dunia bahwa Ia adalah manusia yang sempurna tanpa melakukan dosa (Flp. 2:7; 1 Tim. 3:16; Ibr. 2:14; 1 Yoh. 4:2). Secara natur kemanusiaanya, Ia memiliki darah dan daging manusia. Artinya, Ia dapat dilihat, dapat diraba atau disentuh, dan Ia hidup sebagai manusia sebagaimana manusia pada umumnya hidup. Ia hidup di dalam dunia yang berdosa, tetapi Ia tidak melakukan dosa. Ia hidup di dunia yang membenci-Nya, tetapi Ia mengasihi orang yang membenci-Nya (Luk. 23:33-34). ${ }^{20}$

Dalam inkarnasi-Nya, Yesus turut mengambil bagian dalam penderitaan manusia, menanggung beban manusia dan mempersatukan manusia dengan Allah. Semua ini telah dibuktikan oleh Yesus melalui kehidupan, pelayanan, penderitaan, penyaliban, dan kematian-Nya untuk menyelamatkan manusia yang berdosa. ${ }^{21}$ Puncak inkarnasi Yesus Kristus di bumi adalah menyelamatkan manusia dari dosa dan mengembalikan mereka kepada Allah Bapa. Yesus Kristus merelakan diri menjadi tebusan bagi manusia berdosa, rela disiksa, disalib dan mati di atas bukit golgota (Mrk.10:45).

\section{Prinsip Pelayanan Dalam Inkarnasi Yesus}

Prinsip Pelayanan Kasih

Prinsip yang mendasar dari inkarnasi Yesus adalah pelayanan kasih. Dengan bertumpu kepada kasih-Nya, Yesus merelakan diri melayani bukan untuk dilayani (Yoh.13:1-20;Mark.10:45) dan

${ }^{16}$ Peter Onyekwelu Okafor, "Incarnation As a Fundamental Hermeneutical Principle : The Case of Christian Theology and the Issue of Theological Education in Nigeria," Ministerium - Journal of Contextual Theology 2, no. 1 (2016): 1.

${ }^{17}$ Nainggolan, "Multikulturalisme Untuk Teologi Misi Ramah Kemanusiaan.”230

${ }^{18}$ Peniel C D Maiaweng, “Inkarnasi : Realitas Kemanusiaan Yesus,” Jurnal Jaffray 13, no. 1 (2015). $97-98$

${ }^{19}$ Alexei V. Nesteruk and Alexander V. Soldatov, "Christian Theology, Extraterrestrial Intelligence and a Hypothesis of Multiple Incarnations," Journal of Siberian Federal University - Humanities and Social Sciences 12, no. 6 (2019): 1050, https://doi.org/10.17516/1997-1370-0440.

${ }^{20}$ Maiaweng, "Inkarnasi : Realitas Kemanusiaan Yesus.”100

${ }^{21}$ Ibid. 100 
meletakkan dasar penginjilan untuk mengasihi jiwa-jiwa yang tersesat (Yoh.10:17-18; 13:34-35). ${ }^{22}$ Kasih-Nya menjadi dasar untuk membangun hubungan manusia dengan Allah Pencipta (Yoh.3:16) dan memulihkan hubungan antara sesama manusia. Sehingga melahirkan sikap saling mengasihi dan menunjunjung tinggi harkat dan martabat manusia, memelihara nilai-nilai kebersamaan, sikap saling menghormati, saling memperhatikan dan sikap tolong menolong. (Kel.20:12-17). Kasih-Nya juga memulihkan hubungan manusia dengan dirinya sendiri. Manusia menghargai dirinya sendiri sebagai manusia yang diciptakan se-gambar dan serupa dengan Allah dan diciptakan dengan tujuan tertentu yaitu untuk kemuliaan Allah (Yes.43:7). ${ }^{23}$

\section{Prinsip Pelayanan Transformatif}

Inkarnasi Yesus ke dalam dunia untuk melakukan perubahan (transformasi) bagi kehidupan dunia sesuai dengan standart kerajaan Allah (Mat.10:34). Perubahan yang dilakukan-Nya adalah sangat radikal karena inti dari perubahan tersebut adalah kebenaran Allah dan kepentingan Allah dalam kerajaan-Nya. ${ }^{24}$ Transformasi Yesus menyentuh bagian-bagian kebudayaan Yahudi yang selama ini menjadi acuan tata nilai dan norma dalam kehidupan sehari-hari. Yesus mengubah konsep dan tradisi keagamaan yang antroposentris kepada nilai-nilai agama yang berpusat kepada Allah (Theosentris). Nilai-nilai agama yang Theosentris menempatkan Allah sebagai inti dan pusat dari segala aktifitas kehidupan manusia. Allah adalah tolok ukur dan hanyalah kehendak-Nya yang menjadi tolok ukur kebenaran di dalam dunia ini. ${ }^{25}$

Selain itu transformasi yang dilakukan oleh Yesus bertentangan dengan komunitas religius yang ada dalam konteks lingkungan dimana Yesus melayani. Khususnya di dalam menghadapi Ahliahli Taurat dan orang Farisi. Hal ini disebabkan karena Ahli-ahli Taurat dan orang Farisi menjunjung tinggi nilai-nilai tradisi dari pada kebenaran Allah. Namun bukan berarti Yesus menolak semua adatistiadat yang ada pada waktu itu. ${ }^{26}$ Yesus memiliki sikap dalam menghadapi kebudayaan. Pertama, Christ Against Culture Position yaitu Yesus menolak kebudayaan yang bertentangan dengan keberan Allah. Kedua, Christ Of Culture Position yaitu Yesus tinggal di dalam budaya Yahudi dan hidup dengan cara orang Yahudi. Ketiga, Christ Culture and In Paradoks Position yaitu Yesus dan kebudayaan berada dalam relasi paradoks. Empat, Christ the Transformer of Culture Position yaitu Yesus melakukan transformasi di dalam kebudayaan setempat. ${ }^{27}$ Dalam melakukan transformasi Yesus menggunakan pendekatan yang beragam, sesuai dengan kebutuhan dari UPG (Unreached People Groups) yang sedang dilayani-Nya. Kreatifitas dan keunikan metode yang diciptakan oleh Yesus membuat beberapa pimpinan agama Yahudi merasa iri dan menuduh-Nya memberitakan kebenaran lain di luar tradisi agama Yahudi. Celah inilah yang pada akhirnya mereka gunakan untuk menjerat Yesus dan menyalibkan-Nya.

Beberapa metode yang dilakukan oleh Yesus seperti yang dilaporkan oleh Injil. Pertama, metode edifikasi yang dilakukan lewat perumpamaan. Tujuannya untuk mengilustrasikan realitasrealitas Kerajaan Allah, kepada pendengar pada waktu itu. Sehingga mereka dapat memahami secara cepat berita dan kebenaran kerajaan sorga. ${ }^{28}$ Melalui perumpamaan Yesus menyampaikan kebenaran rohani, prinsip iman dan pelajaran moral. ${ }^{29}$ Kedua, metode pastoral konseling. Dalam hal ini Yesus melakukan dengan "datang dan berjalan bersama mereka" (Luk. 24:15), Yesus "bertanya" (Luk. $24: 17,18)$, Yesus mengajukan pertanyaan yang bersifat bercerita. Pertanyaan terbuka membuat konseli terdorong untuk bercerita, berbeda dengan pertanyaan tertutup yang cukup dijawab singkat: "ya" atau "tidak", "sudah" atau "belum", Yesus "mendengar", Yesus "menerima", Yesus "memperhadapkan mereka dengan persoalan yang sebenarnya" Luk.24:25-26), Yesus "mengajar"

\footnotetext{
${ }^{22}$ George W. Peters, A Biblical Theology of Missions (Malang: Gandum Mas, 2006). 70

${ }^{23}$ Ibid.69-70

${ }^{24}$ Maiaweng, "Inkarnasi : Realitas Kemanusiaan Yesus.”109

${ }^{25}$ David J Bosch, Transformasi Misi Kristen (Jakarta: BPK Gunung Mulia, 1991).55

${ }^{26}$ Maiaweng, "Inkarnasi : Realitas Kemanusiaan Yesus."103

${ }^{27}$ Sudarmanto, Teologi Multikultural.69

${ }^{28}$ Erni Maria Clartje Efruan et al., "Multicultural Counselling With the Technique of Parable a Diacognitive Analysis,” European Journal of Science and Theology 16, no. 1 (2020): 172.

${ }^{29}$ Marulak Pasaribu, Injil Sinoptik (Batu: Departemen Literatur YPPII, 2002).157
} 
(Luk.24:27), Yesus "bersedia tinggal bersama mereka" (Luk. 24:28-29) $\cdot{ }^{30}$ Ketiga, metode apologetik yaitu untuk memberikan jawaban kepada Ahli-ahli Taurat dan orang Farisi yang berusaha menjebak Yesus dalam pertanyaan-pertanyaan mereka (Mat.12:22-37;Mrk.3:20-30;Luk.11:14-23). Pendekatan ini dilakukan-Nya agar konsep dan ideologi yang selama ini melekat dalam kehidupan mereka diarahkan kembali kepada kebenaran seutuhnya yang sesuai dengan nilai-nilai kerajaan Allah. ${ }^{31}$ Keempat, metode mujizat. Yesus melakukan mujizat bukan untuk kepentingan diri-Nya sendiri. Mujizat yang dibuat oleh Yesus, sebagai tanda bahwa kerajaan Allah telah hadir di tengahtengah umat-Nya (Mat.12:39), dan pemenuhan janji-janji tentang kerajaan Mesias sebagaimana telah dinubuatkan oleh para nabi (Yes.24:18-19; 35:5-6; 61:1). ${ }^{32}$

\section{Prinsip Pelayanan Multikultural}

Yesus lahir dalam kebudayaan manusia, khususnya kebudayaan Yahudi. Akan tetapi Ia sangat menghargai kebudayaan lain. Dalam pelayanan-Nya, Yesus melayani dan menyembuhkan suku lain dan melakukan mujizat kepada mereka. Secara sederhana dapat dipahami bahwa selama Yesus berinkarnasi, Ia sangat menghargai nilai-nilai multikultural. Yesus sering sekali menggunakan pendekatan ini untuk menjangkau UPG (Unreached People Groups). Salah satu contoh adalah pelayanan kepada perempuan Samaria. Dalam pelayanan-Nya kepada perempuan Samaria, Yesus menghargai pemahaman perempuan Samaria tentang keselamatan dari prespektifnya sendiri. Kemudian dari pemahaman itu, Yesus menjelaskan berita keselamatan yang sesungguhnya kepada perempuan itu. ${ }^{33}$

Dalam beberapa perumpamaan, Yesus mengangkat tema tentang suku lain. Perumpanaan orang Samaria yang murah hati, adalah isu yang diangkat oleh Tuhan Yesus dalam mengajar bangsa Yahudi dan Ahli-ahli Taurat agar mau menghargai bangsa lain serta mampu mengaplikasikan iman mereka dalam konteks kehidupan sehari-hari. Yesus mengajarkan mereka tentang sikap inklusif dalam pendekatan kepada bangsa lain adalah bukti nyata seseorang mengasihi Allah. Yesus mengajarkan mereka bagaimana sikap untuk menghargai perbedaan keanekaragaman budaya, gender, status sosial, ekonomi dan orientasi agama. ${ }^{34}$ Sehingga dalam perumpamaan ini, sangatlah nampak posisi Yesus sebagai pelayanan yang profesional dalam melakukan konseling yang bersifat multikultur. Yesus mampu menggunakan dialog antarpribadi, intrapersonal, transpersonal dan intratekstual. ${ }^{35}$

\section{Dimensi Inkarnasi Yesus}

\section{Dimensi Theosentris}

Secara sederhana Theosentris berarti berpusat kepada Allah. Hal ini yang didemontrasikan Yesus dalam melakukan pelayanan selama inkarnasi-Nya. Yesus mendemonstrasikan bahwa segala sesuatu harus berpusat kepada Allah sebagai Pencipta langit dan bumi. Hal ini dubuktikan dari inti berita pengajaran-Nya yaitu uraian pengajaran tentang kedaulatan Allah dalam kerajaan-Nya. ${ }^{36}$ Yesus taat terhadap ketetapan Allah dan mengakui providensia Allah pada seluruh tatanan alam semesta, termasuk manusia, hewan dan tumbuh-tumbuhan. Ia menopang, mengatur dan menata kehidupan semua ciptaan-Nya sebaik-baiknya untuk bergerak atau beroperasi sesuai dengan rancangan Allah yang agung. ${ }^{37}$

${ }^{30}$ Erni Maria Clartje Efruan et al., "Multicultural Counselling With the Technique of Parable a Diacognitive Analysis," European Journal of Science and Theology 16, no. 1 (2020): 167-170.

${ }^{31}$ Harming, "Metode Penginjilan Yesus Dalam Injil Yohanes 4 : 1-42," Evangelical 1, no. Penginjilan (2017), 66-67. https://journal.sttsimpson.ac.id/index.php/EJTI/article/view/73.

${ }^{32}$ Pasaribu, Injil Sinoptik.145

${ }^{33}$ Harming, "Metode Penginjilan Yesus Dalam Injil Yohanes 4 : 1-42," Evangelical 1, no. Penginjilan (2017), 168. https://journal.sttsimpson.ac.id/index.php/EJTI/article/view/73.

34 Maria Clartje Efruan et al., "Multicultural Counselling With the Technique of Parable a Diacognitive Analysis."171

${ }^{35}$ Ibid. 175

${ }^{36}$ Bosch, Transformasi Misi Kristen 47

${ }^{37}$ Nainggolan, "Multikulturalisme Untuk Teologi Misi Ramah Kemanusiaan.”224 
Selama melaksanakan pelayanan-Nya, Yesus selalu mengandalkan kuasa dari Allah Pencipta. Yesus menggantungkan segala sesuatu yang dilakukan-Nya sesuai dengan kehendak Allah. Cara yang digunakan Yesus adalah Ia mengasingkan waktu untuk bersekutu dengan Bapa di dalam doa (Mat. 14:23; Luk. 5:16), dan menengadah ke langit untuk memohon belas kasihan Allah dalam pelayanan-Nya (Yoh. 11:42; 17:1-5) ${ }^{38}$ Semua tindakan-Nya itu menggambarkan bahwa Yesus tunduk kepada kedaulatan Allah (Theosentris).

\section{Dimensi Kristosentris}

Yesus adalah poros utama dari inkarnasi, karena Ia secara langsung melakukan proses inkarnasi itu. Dia mau merelakan diri menjadi manusia dan menjadi pelaksana tunggal dan utama dari inkarnasi. Hal ini disaksikan oleh Rasul Paulus di dalam Filipi 2:6-8, bahwa yang walaupun dalam rupa Allah, tidak menganggap kesetaraan dengan Allah itu sebagai milik yang harus dipertahankan, melainkan telah mengosongkan diri-Nya sendiri dan mengambil rupa seorang hamba, dan menjadi sama dengan manusia. Dan dalam keadaan sebagai manusia, Ia telah merendahkan diri-Nya dan taat sampai mati, bahkan sampai mati di kayu salib.

Kata kuncinya adalah "kenotis" atau "mengosongkan diri". Paulus melihat kenotis sebagai sifat Kristus, yang dengan mengosongkan diri berpadu dengan dunia manusia. Dalam kenotis, Yesus mengambil status manusia untuk menjadi hamba dan solider utuh dengan manusia dalam menanggung dosa-dosa umat manusia. Dalam solidaritas kenotis inilah Yesus mengadakan pembebasan untuk membawa manusia yang terhilang kembali kepada Allah (Ef. 4:8-10). ${ }^{39}$ Kevin J. Conner menuliskan sembilan alasan inkarnasi Yesus. Pertama, meneguhkan janji-janji keselamatan yang dibuat kepada bapa-bapa leluhur (Adam, Nuh, Abraham, Ishak dan Yakub). Kedua, untuk menggenapi Hukum Taurat, Mazmur dan Nabi-Nabi. Ketiga, memberikan pewahyuan yang lengkap tentang Allah Bapa. Keempat, untuk menghancurkan perbuatan iblis dan kerajaannya. Kelima, untuk menjalani kehidupan manusia yang sempurna tanpa dosa. Keenam, untuk menyingkirkan dosa melalui pengorbanan diri-Nya. Ketujuh, untuk mewujudkan perjanjian baru. Kedelapan, untuk menggenapi jabatan-jabatan Perjanjian Lama (Hakim, Nabi, Imam dan Raja). Kesembilan, untuk menyelesaikan rencana penebusan dalam kedatangan-Nya yang kedua. ${ }^{40}$

Bukti nyata dari hal di atas adalah Yesus Kristus secara ikhlas merelakan diri dikandung oleh anak dara Maria (Mat.1:18-25 ; Luk.2:1-7). Melayani dengan fasilitas yang sangat terbatas dan tidak menuntut penghormatan dari manusia. ${ }^{41}$ Yesus melakukan transformasi sosial-spiritual-cultural demi keselamatan di dalam dunia ini. Ia berinkarnasi bukan mencari ketenaran atau kemuliaan. Sebaliknya datang untuk melayani manusia dan memberikan jaminan keselamatan atas nama-Nya sendiri. Yesus berkata "Akulah jalan dan kebenaran dan hidup. Tidak ada seorang pun yang datang kepada Bapa, kalau tidak melalui Aku". (Yoh.14:6).

\section{Dimensi Soteriologis}

Charles C. Ryrie menuliskan bahwa dari sudut pandang Allah, keselamatan meliputi segenap karya Allah dalam membawa manusia keluar dari hukuman menuju pembenaran, dari kematian kepada kehidupan yang kekal, dari musuh atau seteru menjadi anak-anak Allah. Dari sudut pandang manusia, keselamatan mencangkup segala berkat yang berada di dalam Kristus, yang bisa diperoleh dalam kehidupan sekarang maupun kehidupan yang akan datang. ${ }^{42}$ Artinya, misi inkarnasi Yesus adalah melaksanakan keselamatan kepada umat manusia, sebagaimaa kehendak Allah Pencipta bagiNya. ${ }^{43}$

Maka Lumintang menuliskan bahwa aspek keselamatan yang dilakukan oleh Yesus adalah holistik dengan memperhatikan beberapa unsur. Pertama, kondisi manusia yang berbahaya artinya

\footnotetext{
${ }^{38}$ Maiaweng, "Inkarnasi : Realitas Kemanusiaan Yesus.”109

${ }^{39}$ Yakob Tomatala, Teologi Kontekstualisasi (Malang: Gandum Mas, 2001). 26

${ }^{40}$ Kevin J Conner, A Practical Guide To Christian Belief (Malang: Gandum Mas, 2004). 384-391

${ }^{41}$ Charles L. O’Donnell, "The Presence of God," Thought 38, no. 2 (2017): 230-234.

${ }^{42}$ Charles C Ryrie, Teologi Dasar 2 (Yogyakarta: Andi, 2008). 15

${ }^{43}$ Maiaweng, "Inkarnasi : Realitas Kemanusiaan Yesus.”119
} 
manusia telah rusak karena dosa. Kedua, kabar baik yang berpusat pada Yesus yang membebasakan manusia dari dosa. Ketiga, Injil dan tanggung jawab sosial dimana setiap orang percaya dipanggil untuk melibatkan diri dalam pelayanan kasih, tuntutan keadilan dan perdamaian. ${ }^{44}$

\section{Dimensi Ekklesiologis}

Yesus menyatakan di dalam Matius 16: 18 Kristus bahwa di atas batu karang ini, Aku akan mendirikan gereja-Ku. Pernyataan ini merupakan hal yang harus diingat oleh orang percaya sepenjang masa, sebab di atas batu karang Yesus membangun gereja-Nya dan akan berkembang sesuai dengan standar ilahi. ${ }^{45}$ Gereja itu bukanlah gereja gedung ataupun organisasi maupun ordinansi gereja. Gereja yang dimaksud adalah kehadiran Kerajaan Allah di dalam kehidupan pribadi orang percaya dan Allah memakai gereja-Nya untuk menjangkau UPG (Unreached People Groups) untuk mengenal Kerajaan-Nya. ${ }^{46}$

Gereja yang dibangun oleh Yesus, menunjukkan eratnya ikatan persatuan orang-orang percaya. Anggota tubuh yang bermacam-macam diperlukan untuk kepentingan masing-masing anggota supaya tubuh itu dapat berfungsi secara efisien.$^{47}$ Kesatuan ini harus didorong oleh rasa saling mengasihi sebagai saudara di dalam Tuhan dan memiliki satu visi yang jelas bahwa segala sesuatu yang dilakukan adalah untuk kemuliaan Tuhan Yesus Kristus. Dalam hal ini, gereja tidak mampu hidup apabila berdiri sendiri tetapi memerlukan penolong dan penopang sehingga proyek Tuhan Yesus Kristus atas dunia ini dapat terselesaikan dengan baik.

\section{Dimensi Misiologis}

Maiaweng menuliskan bahwa dengan adanya para rasul yang telah dihasilkan oleh Yesus melalui pemilihan dan pembentukan yang telah telah dilaksanakan-Nya menjadi kunci penyebaran Injil sejak terbentuknya kekristenan. Injil telah diberitakan sampai ke ujung bumi dan setiap suku bangsa dapat mengenal Yesus sebagai Juruselamat. Dengan demikian, inkarnasi Yesus telah menjadi sejarah yang berhubungan langsung dengan keselamatan manusia dan menjadi dasar kontinuitas pemberitaan Injil. ${ }^{48}$

Aspek misiologis dalam inkarnasi Yesus sebagai berikut. Pertama, Yesus melihat diri-Nya sebagai Pemberita yang diurapi Allah yang datang untuk melakukan pekerjaan sebagai Imam, Raja, Nabi. Kedua, Yesus melihat diri-Nya sebagai Pemberita yang diutus dengan suatu berita dengan tugas Apostolik. Tugas ini menyangkut pembebasan dalam segala bidang atau pembebasan total yaitu meliputi segi materi dan non-materi manusia itu dari kuasa dosa (Galatia 5:1). Ketiga, Yesus melihat diri-Nya sebagai penyataan pemerintahan Allah. Kehadiran-Nya di bumi adalah sebagai tanda bahwa kerajaan Allah memulai babak pembebasan dan penguasaannya secara baru di bumi (Matius 16:21-28 ; Markus 8:31 ; Lukas 9:22-27). ${ }^{49}$

Artinya Yesus berinkarnasi untuk melaksanakan misi Kerajaan Allah bagi yang terhilang. Dalam menjalankan misi ini, Yesus tidak membedakan status dan hirarki seseorang. Yesus melihat tiap-tiap orang membutuhkan kasih Bapa yang seutuhnya. Yesus sangat menghormati nilai-nilai demokrasi dan tidak pernah memaksakan kehendak kepada siapapun. Melaksanaka misi itu dengan kasih, perhatian dan empati. Selain itu, Tuhan Yesus Kristus melaksanakan tugas misi-Nya dengan seutuhnya atau holistik. Dimana misi yang dilakukan-Nya bukan hanya berkenaan dengan proklamasi Injil, tetapi juga berkenaan dengan pelepasan manusia dari ketidakadilan.

\footnotetext{
${ }^{44}$ Lumintang, Misiologia Kontemporer. 43

${ }^{45}$ Prayogi, "Mencari Esensi Dan Misi Gereja Dalam Konteks Indonesia Awal Abad 21."40

${ }^{46}$ Nainggolan, "Multikulturalisme Untuk Teologi Misi Ramah Kemanusiaan.”231

${ }^{47}$ Prayogi, "Mencari Esensi Dan Misi Gereja Dalam Konteks Indonesia Awal Abad 21."50-51

${ }^{48}$ Maiaweng, "Inkarnasi : Realitas Kemanusiaan Yesus."119

${ }^{49}$ Bosch, Transformasi Misi Kristen.47-54
} 


\section{Model-Model Penginjilan untuk Konteks Multikultural}

\section{Model Membangun Hubungan Kekeluargaan Dengan UPG (Unreached People Groups)}

Model penginjilan yang semestinya dilakukan di Indonesia adalah model penginjilan dengan membangun relasi dengan siapa pun sampai pada tahap Penginjil menjadi bagian dari keluarga UPG (Unreached People Groups). Dengan demikian, penginjil diberikan akses lebih jauh oleh UPG (Unreached People Groups), untuk memahami mereka dari sudut pandang mereka sendiri. Sudut pandang ini, bisa berhubungan dengan nilai-nilai kebudayaan mereka, filosofis kehidupan mereka, tata cara tradisi keyakinan dan keagamaan yang sedang mereka yakini. ${ }^{50}$ Dengan memahami mereka secara komprehensif, para penginjil terhindar dari sikap menghakimi dan membuka jalan raya di dalam memberitakan kerajaan Allah. Para penginjil juga mampu memberikan jalan keluar yang tepat sesuai dengan nilai-nilai Alkitab dan sesuai dengan konteks UPG (Unreached People Groups).

Kunci utama dalam membangun relasi adalah kerelaan untuk menjadi "seperti" atau "menjadi bagian" dari UPG (Unreached People Groups). Menjadi bagian dari mereka, bukan berarti ikut tata cara, tata nilai ataupun kebiasaan yang salah dari UPG (Unreached People Groups) yang bertentangan dengan kebenaran Alkitab. Sebaliknya hal-hal yang kurang tepat itu dievaluasi dan dikuduskan oleh firman Allah, kemudian disampaikan hal yang benar sesuai sudut pandang Alkitab. Atau juga ada nilai-nilai kebudayaan yang sesuai atau sejalan dengan nilai-nilai kebenaran Alkitab, dikembangkan atau dijadikan alat untuk memuliakan Allah. Dalam mengambil keputusan seperti ini para penginjil dan misionaris haruslah bijak memilah-milah kebudayaan dari UPG (Unreached People Groups) yang harus ditolak, dikuduskan ataupun diterima.

\section{Model Pelayanan Memperjuangkan Nilai-Nilai Kesetaraan, Keadilan dan Kebebasan.}

Bangsa Indonesia saat ini sedang menghadapi persoalan diskriminasi kesetaraan, keadilan dan kebebasan. Khususnya hal ini dialami oleh golongan menengah ke bawah. Mereka berada dalam status krisis sosial, pendidikan dan ekonomi. Mereka inilah yang memerlukan perhatian dan diperjuangkan hak-haknya sebagai manusia yang bermartabat. ${ }^{51}$ Para penginjil haruslah mengambil kesempatan ini dengan membawa berita Kerajaan Allah lewat pendidikan, kesehatan, ekonomi dan perjuangan hak-hak asasi manusia. ${ }^{52}$ Penginjil harus menjadi solution maker dalam bidang-bidang ini. Hal inilah yang dilakukan oleh Yesus selama inkarnasi menjamah seluruh sisi kehidupan manusia baik yang berhubungan dengan nilai-nilai spriritual, maupun perjungan ekonomi, hukum, sosial, kesehatan dan hak asasi manusia.

Berbagai contoh dipaparkan oleh para penulis Injil. Yesus memulihkan status sosial Matius pemungut cukai dengan menjadikannya sebagai murid-Nya (Mat.9:9-13; Mrk.2:13-17; Luk; 5:2732) dan membuat Zakeus bersukacita karena Yesus mau menumpang ke rumahnya (Luk.19:1-10). Dimana profesi pemungut cukai adalah profesi yang sangat dibenci oleh orang Yahudi dan dianggap orang-orang berdosa. Karena biasanya pemungut cukai dianggap bagian dari pemerintahan Romawi yang korup. Yesus mau berinteraksi dengan perempuan perempuan Kanaan dan melakukan mujizat padanya sehingga perempuan Kanaan itu percaya kepada Yesus (Mat.15:21-28; Mrk.7:24-30). Yesus menghargai anak-anak kecil yang dianggap remeh oleh orang Yahudi pada waktu itu. Yesus memberkati anak-anak itu dan mendoakan mereka (Mat.19:13-15; Mrk.10:13-16;Luk.18:15-17). Memberikan kesempatan kepada para gembala, sebagai kaum marginal dan terpinggirkan menerima berita pertama kelahiran-Nya (Luk.2:8-20).

\section{Model Pelayanan Dialog-Proklamasi Injil}

Dewasa ini ada dua macam dialog yang sedang dikembangkan di Indonesia. Pertama, dialog lintas agama dengan pluralistik ideologis dengan menghilangkan klaim-klaim finalitas masing-masing

\footnotetext{
${ }^{50}$ Widjaja, "Pluralitas Dan Tantangan Misi : Kerangka Konseptual Untuk Pendidikan Agama."9

${ }^{51}$ Oktavianus Heri Prasetyo Nugroho, "Meretas Damai Di Tengah Keberagaman : Mengembangkan Pendidikan Kristiani Untuk Perdamaian Dalam Perspektif Multikulturalisme," Gema Teologi 38, no. 2 (2014): 164.

${ }^{52}$ Prayogi, "Mencari Esensi Dan Misi Gereja Dalam Konteks Indonesia Awal Abad 21.”41
} 
agama dan aliran kepercayaan, dan berusaha mencari titik temu dalam arah menjaga toleransi diantara sesama anak bangsa. Kedua, dialog lintas agama dengan pendekatan apologetika. Dialog ini suatu pendekatan yang dirancang untuk mendiskusikan suatu topik dalam agama tertentu, kemudian didiskusikan secara bersama-sama. Walaupun pada dasarnya temanya adalah diskusi antara dua kelompok yang berbeda keyakinan, namun pendekatan ini cenderung mengarah ke arah debat. Sehingga konten diskusi terkadang hilang dan yang nampak adalah saling merendahkan dan saling menghina satu dengan yang lain.

Metode yang digunakan Yesus dalam Perjanjian Baru adalah metode dialog proklamatif. Metode ini adalah kegiatan komunikasi timbal balik antara Yesus dengan UPG (Unreached People Groups) baik dalam jumlah banyak maupun personal. Yesus membuka ruang diskusi, menerima dan memberikan tanggapan terhadap sudut pandang dari UPG (Unreached People Groups). Kemudian menganalisis, mengevaluasi, mengajukan pertanyaan dan menolak konsep-konsep itu dengan sikap yang persuasif. Dalam dialog Yesus tidak kompromi dengan dosa atau mengurangi nilai-nilai kebenaran untuk menjaga perasaan dari UPG (Unreached People Groups) atau berusaha mencari titik temu dengan kayakinan iman dari UPG (Unreached People Groups). Demikian juga di dalam dialog, Yesus sedapat mungkin menghindari perdebatan yang konfrontatif. Yesus memberikan kesempatan kepada UPG (Unreached People Groups) untuk menyampaikan pendapat dan Ia sangat menghargai pendapat dan opsi-opsi pemikiran dari UPG (Unreached People Groups), kemudian berusaha menggiringnya kepada inti kebenaran dari Alkitab.

Metode ini juga patut dicontoh oleh penginjil untuk diaplikasikan dalam konteks bangsa Indonesia. Apalagi bangsa Indonesia mengakui lima agama yang berbeda yaitu Islam, Kristen Protestan, Kristen Khatolik, Budha dan Hindu. Dimana masing-masing agama memiliki klaim-klaim finalitas masing-masing. Klaim-klaim finalitas ini tidak bisa dipertemukan titik temunya, karena berbeda sumber, hakikat, ideologi dan ekspresi-ekspresi keagamaan. Justru kalau disatukan atau dicari titik temu, menghasilkan sesuatu yang baru dimana substansinya berbeda dengan yang lama. Jadi biarkanlah keyakinan lama itu melekat dan menjadi keunikan dari agama tertentu. Tugas penginjil adalah menggiring konsep-konsep keagamaan yang lama itu kepada kebenaran-kebenaran Allah seperti yang tertulis di dalam Alkitab.

Juga bangsa Indonesia adalah bangsa yang ramah dan menjunjung tinggi nilai-nilai budaya saling menghargai satu dengan yang lainnya. Jikalau ada perdebatan, apalagi berhubungan dengan keyakinan iman yang dianutnya akan menghasilkan sikap saling membenci. Dialog dengan model pendekatan apologetik adalah warisan dari budaya teologi Barat, yang sama sekali tidak cocok dalam budaya Indonesia. Dialog proklamatif adalah model dialog yang lebih menekankan pendekatan persuasif dan bukan konfrontatif, tetapi isi dan substansinya bersifat proklamatif. Dalam proses interaksi dan dialog lebih mengedepankan sikap saling menghargai satu dengan yang lain. Pada titik inilah, penginjil harus benar-benar menguasai tema diskusi dan konsep-konsep dari UPG (Unreached People Groups). Kemudian menggiring topik itu secara sabar dan simultan kepada nilai-nilai kebenaran Allah. Model dialog proklamatif adalah pendekatan yang dipergunakan Yesus untuk melayani Perempuan Samaria (Yoh.4:1-42). ${ }^{53}$

\section{KESIMPULAN}

Inkarnasi Yesus adalah doktrin yang paling pokok dalam kekristenan karena menyangkut fakta sejarah dari iman Kristen. Dalam inkarnasi-Nya, Yesus turut mengambil bagian dalam penderitaan manusia, menanggung beban manusia dan mempersatukan manusia dengan Allah. Semua ini telah dibuktikan oleh Yesus melalui kehidupan, pelayanan, penderitaan, penyaliban, dan kematian-Nya untuk menyelamatkan manusia yang berdosa.

Prinsip-prinsip inkarnasi Yesus, menjadi model dalam pelayanan penginjilan kepada bangsa yang multikultur, karena Yesus sebagai Penginjil Agung telah melakukannya selama melayani di dunia ini. Praktik dari penginjilan dalam inkarnasi-Nya tidak bertentangan dengan nilai-nilai

53 Maria Clartje Efruan et al., "Multicultural Counselling With the Technique of Parable a Diacognitive Analysis.”165-176 
kebenaran Allah dan menjawab kebutuhan konteks waktu itu. Prinsip-prinsip pelayanan Yesus dalam inkarnasi-Nya cocok digunakan dalam konteks bangsa Indonesia yang multikultur. Dimana menghasilkan tiga model penginjilan yaitu model membangun hubungan kekeluargaan dengan UPG (Unreached People Groups), model pelayanan memperjuangkan nilai-nilai kesetaraan-keadilankebebasan, dan model pelayanan dialog-proklamasi Injil

\section{REFERENSI}

Bosch, David J. Transformasi Misi Kristen. Jakarta: BPK Gunung Mulia, 1991.

Brown, Christia Spears, Michelle Tam, and Frances Aboud. "Ethnic Prejudice in Young Children in Indonesia: Intervention Attempts Using Multicultural Friendship Stories." International Journal of Early Childhood 50, no. 1 (2018): 67-84.

Conner, Kevin J. A Practical Guide To Christian Belief. Malang: Gandum Mas, 2004.

Dawa, Markus Dominggus L. "Menjadi Jemaat Multikultural : Suatu Visi Untuk Gereja-Gereja Tionghoa Injili Indonesia Yang Hidup Di Tengah Konflik Etnis Dan Diskriminasi Rasial.” Veritas: Jurnal Teologi dan Pelayanan 7, no. 1 (2006): 127-144.

Harming. "Metode Penginjilan Yesus Dalam Injil Yohanes 4 : 1-42.” Evangelical 1, no. Penginjilan (2017).

Hum, Yan Chai. "Literature Reviews." In SpringerBriefs in Applied Sciences and Technology, 1145, 2013.

Lumintang, Stevri Indra. Misiologia Kontemporer. 1st ed. Batu: Departemen Literatur PPII, 2006.

Maiaweng, Peniel C D. "Inkarnasi : Realitas Kemanusiaan Yesus.” Jurnal Jaffray 13, no. 1 (2015).

Maria Clartje Efruan, Erni, Zummy Anselmus Dami, David Samuel Latupeirissa, and Mesakh Abia Pello Dethan. "Multicultural Counselling With the Technique of Parable a Diacognitive Analysis." European Journal of Science and Theology 16, no. 1 (2020): 165-176.

Nainggolan, Desiana M. "Multikulturalisme Untuk Teologi Misi Ramah Kemanusiaan.” Jurnal Teologi Stulos 17, no. 2 (2019).

Nesteruk, Alexei V., and Alexander V. Soldatov. "Christian Theology, Extraterrestrial Intelligence and a Hypothesis of Multiple Incarnations." Journal of Siberian Federal University Humanities and Social Sciences 12, no. 6 (2019): 1048-1071.

Nugroho, Oktavianus Heri Prasetyo. "Meretas Damai Di Tengah Keberagaman : Mengembangkan Pendidikan Kristiani Untuk Perdamaian Dalam Perspektif Multikulturalisme." Gema Teologi 38, no. 2 (2014): 143-170.

O’Donnell, Charles L. “The Presence of God.” Thought 38, no. 2 (2017): 230-234.

Okafor, Peter Onyekwelu. "Incarnation As a Fundamental Hermeneutical Principle: The Case of Christian Theology and the Issue of Theological Education in Nigeria." Ministerium Journal of Contextual Theology 2, no. 1 (2016): 1-23.

Pasaribu, Marulak. Injil Sinoptik. Batu: Departemen Literatur YPPII, 2002.

Paul, Emily. "Incarnation, Modality Timelessness , And" (2019): 88-112.

Peters, George W. A Biblical Theology of Missions. Malang: Gandum Mas, 2006.

Prayogi, Winfrid. "Mencari Esensi Dan Misi Gereja Dalam Konteks Indonesia Awal Abad 21." Veritas : Jurnal Teologi dan Pelayanan 1, no. 1 (2000): 39-51.

Ryrie, Charles C. Teologi Dasar 2. Yogyakarta: Andi, 2008.

Sadono, Sentot. "Misi Injili Dalam Konteks Masyarakat Indonesia Yang Majemuk." In Holistic Global Mission. Batu: Departemen Literatur YPPII, 2007.

Silitonga, Roedy. “Amanat Agung Dan Kemajemukan Agama.” Jurnal Teologi Stulos 16, no. Misi (2018): 69-89.

Sudarmanto, Gunaryo. Teologi Multikultural. Edited by Dina Elisabeth Latumahina. 1st ed. Batu: 
Departemen Multi-Media YPPII Batu, 2014.

Tomatala, Yakob. Teologi Kontekstualisasi. Malang: Gandum Mas, 2001.

Widjaja, Fransiskus Irwan. "Pluralitas Dan Tantangan Misi : Kerangka Konseptual Untuk Pendidikan Agama" 4 (2019).

Zaluchu, Sonny Eli. "Strategi Penelitian Kualitatif Dan Kuantitatif Di Dalam Penelitian Agama." Evangelikal 4, no. 1 (2020): 28-38. 